\title{
EVALUASI SEDIAAN FISIK EMULGEL MENGANDUNG MINYAK ATSIRI RIMPANG TEMU PUTIH (Curcuma zedoaria, (Berg.) Roscoe)
}

\author{
EVALUATION OF PHYSICAL FORM ESSENTIAL OIL \\ CONTAINING EMULGEL RHIZOME TEMU PUTIH \\ (Curcuma zedoaria, (Berg.) Roscoe)
}

\author{
Nur Mahdi*, Diky Mudhakir, Dolih Gozali \\ Sekolah Tinggi Ilmu Kesehatan Darul Azhar Batulicin \\ Jl. Batu Benawa, Simpang Empat, Tanah Bumbu, Kalimantan Selatan 72171 \\ *Penulis Korespodensi, email: nurmahdi.apt@gmail.com
}

\begin{abstract}
ABSTRAK
Temu putih atau disebut juga kunir putih merupakan salah satu spesies dari famili Zingiberaceae yang telah dikomersilkan penggunaan rimpangnya sebagai tanaman obat. Komponen terbesar dari rimpang temu putih, yaitu minyak atsiri yang mempunyai efek antiinflamasi. Penggunaan rimpang temu putih sebagai antiinflamasi di masyarakat masih secara empiris, dengan mengoleskan air perahan rimpang temu putih pada kulit. Untuk meningkatkan efektivitas penggunaan minyak atsiri yang terkandung dalam temu putih, dilakukan formulasi emulgel yang mengandung minyak atsiri dengan penambahan PEG 8 beeswax agar didapat sediaan emulgel yang stabil, baik dan aman digunakan. Tahap penelitian yang dilakukan meliputi penyiapan bahan, determinasi bahan, skrining fitokimia, destilasi menggunakan uap-air, analisis komponen kimia dengan GC-MS, serta uji kualitatif minyak atsiri dengan sediaan emulgel yang mengandung minyak atsiri, formulasi emulgel mengandung minyak atsiri dengan menggunakan emulsifying wax konsentrasi 6,5\%, 7\%, 7,5\%, dan 8\%. Evaluasi sediaan meliputi pengamatan organoleptik, $\mathrm{pH}$, viskositas, sentrifugasi, serta uji hedonik sediaan. Berdasarkan hasil evaluasi pengamatan organoleptik, $\mathrm{pH}$, viskositas, sentrifugasi, serta uji hedonik sediaan menunjukkan bahwa kestabilan dalam batas rentang yang dibolehkan. Formulasi emulgel yang terbaik ditunjukkan pada formula ke4 pada konsentrasi PEG 8 beeswax $8 \%$.
\end{abstract}

Kata kunci: emulgel, minyak atsiri, rimpang temu putih, evaluasi

\section{ABSTRACT}

Temu putih (Curcuma zedoaria (Berg.) Roscoe) or also called white turmeric is one the species of the family Zingiberaceae rhizome that has been commercially used as a medicinal plant. The largest component of the rhizome temu putih, namely essential oil, it has anti-inflammatory. The use of temu putih rhizome as anti-inflammatory in the community is still empirically, by applying water to the skin milking of temu putih rhizome. To improve the effectiveness of the use of essential oil containing temu putih rhizome was performed, emulgel containing essential oil was formulated by adding of 
PEG 8 beeswax to obtain a stable, good and safe emulgel to use. Stage of research was conducted by preparing of materials, such as materials detemination, phytochemical screening, distillation using steam-water, chemical component analysis by GC-MS, qualitative test with a preparation of essential oil that contain essential oils emulgel, emulgel formulations containing essential oil using emulsifying wax concentration of $6.5 \%, 7 \%, 7.5 \%$, and $8 \%$. The evaluation preparations include observation of organoleptic, $\mathrm{pH}$, viscosity, centrifugation and hedonic test preparations. The results evaluation observations of organoleptic, $\mathrm{pH}$, viscosity, centrifugation, and the hedonic test preparations, showing stability within the allowed range. Emulgel formulations which best shown in the fourth formula at a concentration of PEG 8 beeswax $8 \%$.

Keywords: Emulgel, Temu Putih, Essential Oil, Evaluation

\section{PENDAHULUAN}

Pengenalan dan penggunaan tanaman obat berkhasiat sejak zaman dahulu oleh masyarakat Indonesia adalah sebagai salah satu upaya untuk menanggulangi berbagai masalah kesehatan, jauh sebelum pelayanan kesehatan formal dan obat-obatan modern menyentuh lapisan masyarakat. Penggunaan tanaman obat untuk penyembuhan suatu penyakit didasarkan pada pengalaman yang secara turun-temurun diwariskan oleh generasi terdahulu kepada generasi berikutnya yang lebih dikenal sebagai obat tradisional. Saat ini pemilihan bahan-bahan alami untuk pengobatan didasarkan pada bukti penelitian (evidence based), sehingga penggunaan bahan-bahan alami diharapkan dapat lebih tepat sasaran dalam dunia pengobatan. Tanaman berkhasiat obat mempunyai nilai lebih ekonomis dan efek samping lebih kecil dibandingkan dengan obat-obat sintesis, karena itu penggunaan tumbuhan obat dengan formulasi yang tepat sangat penting dan tentunya lebih aman dan efektif (Wasitaatmadja, 1997).

Rimpang temu putih mengandung 1,0-2,50\% minyak atsiri yang terdiri dari monoterpen yang berkhasiat sebagai antineoplastik (antikanker) dan telah terbukti dapat menonaktifkan pertumbuhan sel kanker payudara dan seskuiterpen sebagai komponen utamanya. Minyak atsiri tersebut mengandung lebih dari 20 komponen, diantaranya kurzerenon (zedoarin) yang merupakan komponen terbesar, kurkumin yang berkhasiat sebagai antiradang dan antioksidan yang dapat mencegah kerusakan gen, epikurminol yang berkhasiat sebagai antitumor, kurkuminol yang berkhasiat sebagai hepatoprotektor (pelindung hati), dan zingiberene (Rita, 2010).

Emulgel merupakan emulsi, baik dari air dalam minyak atau minyak dalam air yang dicampur dengan bahan pembentuk gel (gelling agent) (Meenakshi, 2013). Emulgel pada penggunaan dermatologis memiliki beberapa sifat yang menguntungkan seperti thixotropic, greaseless, mudah menyebar, mudah dicuci, lembut, bersih, larut dalam air, daya simpan yang lebih lama, bio-friendly, penampilan transparan, dan menarik (Singla, Saini, Joshi, \& Rana, 2012).

Hasil penelitian yang telah dilakukan oleh Soewarni Mansjoer (1997), menunjukkan bahwa rimpang temu putih mengandung minyak atsiri mempunyai aktivitas antiradang terhadap udem buatan pada tikus putih betina galur Wistar. Penelitian tersebut menunjukkan bahwa efek antiradang $800 \mathrm{mg}$ minyak atsiri/Kg bobot badan setara dengan $30 \mathrm{mg}$ kurkumin/Kg bobot badan (Mansjoer, 1997). 
Berdasarkan uraian di atas, untuk meningkatkan efektivitas penggunaan minyak atsiri pada kulit, dilakukan formulasi minyak atsiri dalam sediaan emulgel. Bentuk sediaan emulgel lebih mudah digunakan dan penyebarannya di kulit juga mudah, dilihat juga dari warna yang menarik, sehingga banyak pasien yang lebih memilih menggunakan produk kosmetik dalam bentuk emulgel dibandingkan sediaan lainnya (Rosyad, 2009). Penelitian ini bertujuan untuk membuat sediaan berupa emulgel yang mengandung minyak atsiri rimpang temu putih (Curcuma zedoaria, (Christm.) Roscoe) dan diuji sifat fisiknya sehingga diperoleh sediaan yang stabil, baik, dan aman digunakan.

\section{METODE PENELITIAN}

\section{Bahan dan Alat}

Alat-alat yang digunakan adalah alat sentrifugasi (Hettich Zentrifugen EBA 20), magnetic stirrer, $\mathrm{pH}$ meter (Mettler Toledo), timbangan digital (Mettler Toledo), viskometer (Brookfield), ultraturrax (IKA), serta alat-alat gelas yang umum digunakan dalam pembuatan sediaan farmasi.

Simplisia yang digunakan dalam penelitian ini adalah minyak atsiri rimpang temu putih (Curcuma zedoaria (Christm.) Roscoe) yang berasal dari Samigaluh, Kulon Progo, Jawa Tengah. Bahan yang digunakan dalam penelitian adalah Carbophol 940 (Bratachem), PEG 8 beeswax (Gattefosse-PT. Menjangan Sakti), paraffin liquid (Bratachem), trietanolamin (Bratachem), DMDM hydantoin (Quadrant), dan akuades.

\section{Jalannya Penelitian}

Penelitian ini merupakan penelitian eksperimental, untuk memformulasikan minyak atsiri rimpang temu putih (Curcuma zedoaria (Christm.) Roscoe) ke dalam sediaan emulgel. Pada penelitian ini, dilakukan uji karakteristik awal yaitu skrining fitokimia untuk mengidentifikasi golongan senyawa kimia yang terkandung. Pengambilan minyak atsiri rimpang temu putih menggunakan metode destilasi uap-air. Kemudian dilakukan penentuan bobot jenis, indeks bias, serta analisis komponen minyak atsiri rimpang temu putih dengan menggunakan Gas Chromatograph-Mass Spectrometer (GC-MS). Uji kualitatif kandungan zat aktif dengan metode Kromatografi Lapis Tipis (KLT) dengan menggunakan pengembang n-heksan:etil asetat (9:1) pada minyak atsiri dan sediaan emulgel yang mengandung minyak atsiri rimpang temu putih.

Pemeriksaan bahan tambahan menurut sertifikat analisis atau data dari Handbook of Pharmaceutical Excipient yang meliputi sifat pemerian dan kelarutan. Pemilihan konsentrasi emulsifying wax untuk mendapatkan konsentrasi paling stabil untuk pembuatan sediaan emulgel yang mengandung minyak atsiri rimpang temu putih. Uji evaluasi sediaan meliputi pengujian organoleptik, $\mathrm{pH}$, viskositas, pengamatan sentrifugasi, dan uji hedonik pada sediaan. Pengolahan dan analisis data dilakukan dengan metode statistik Desain Faktor Eksperimen Analysis of Variation (ANOVA) menggunakan SPSS.

\section{HASIL DAN PEMBAHASAN}

Pada formulasi sediaan emulgel ini digunakan minyak atsiri rimpang temu putih sebagai zat aktifnya. Rimpang temu putih yang digunakan diperoleh dari Samigaluh, 
Kulon Progo, Jawa Tengah yang berumur 6 bulan dipanen. Selanjutnya, dilakukan skrining fitokimia dari rimpang temu putih yang bertujuan untuk mengetahui kandungan metabolit sekunder dari rimpang temu putih. Hasil menunjukkan bahwa rimpang temu putih mengandung metabolit sekunder, seperti yang ditunjukkan pada Tabel I.

Tabel I. Hasil skrining fitokimia

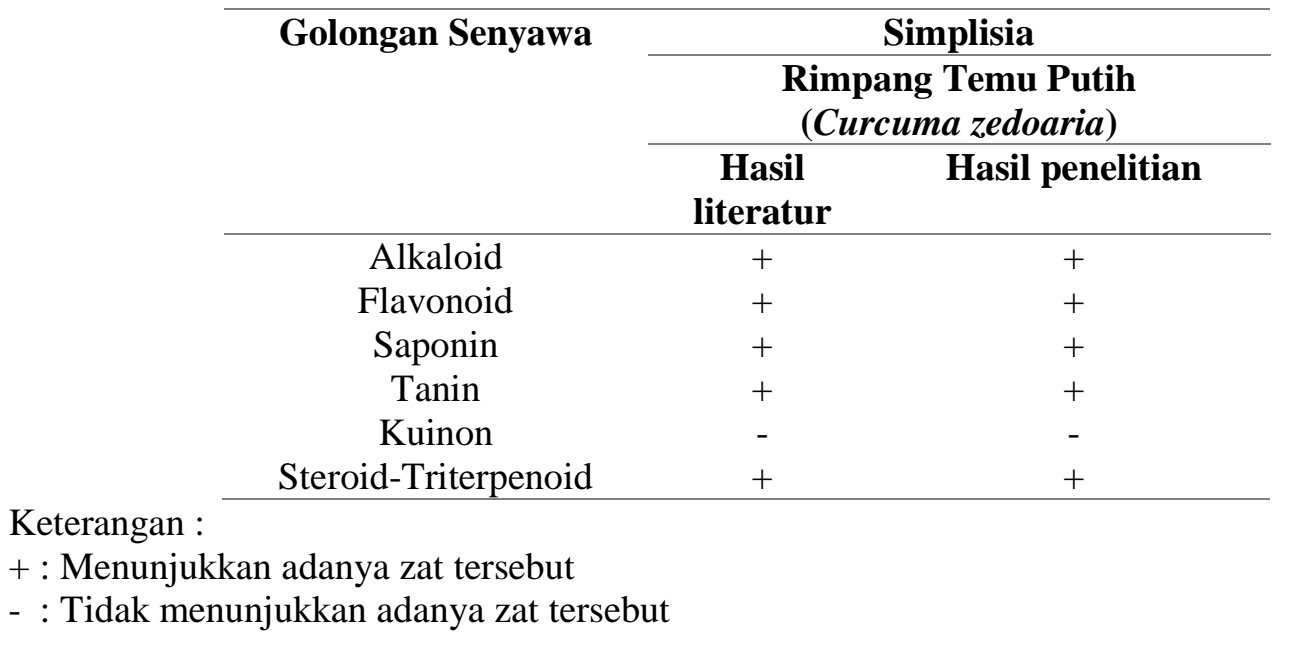

Pengambilan minyak atsiri didahului dengan sortasi rimpang temu putih segar, kemudian mencuci rimpang pada air mengalir, rimpang segar ditimbang, rimpang dipotong dengan ukuran lebar $5 \mathrm{~mm}$, dikeringkan dalam oven digital suhu $45--{ }^{0} \mathrm{C}$ dan didapatkan berat simplisia kering sebesar 4.790 gram. Simplisia kering kemudian dimasukkan ke dalam ketel destilasi, disuling selama 4 jam. Setelah api dimatikan, didinginkan dahulu beberapa saat, kemudian volume dalam separator dibaca. Minyak atsiri yang telah didapatkan kemudian dituang dan ditambahkan natrium sulfat anhidrat sebanyak 1 gram. Kadar minyak atsiri yang diperoleh sebanyak 21,7 mL dengan rendemen $0,56 \%$.

Tabel II. Hasil analisis sifat fisika minyak atsiri rimpang temu putih

\begin{tabular}{cc}
\hline Analisis Fisika & Hasil \\
\hline Berat Jenis & $0,9144 \mathrm{~g} / \mathrm{mL}$ \\
Indeks Bias & 1,5021 \\
\hline
\end{tabular}

Berat jenis minyak atsiri rimpang temu putih pada Tabel II menunjukkan perbandingan antara kerapatan minyak atsiri dengan kerapatan air pada volume dan kondisi yang sama selama pengukuran. Hasil pengukuran berat jenis minyak atsiri dari rimpang temu putih yaitu sebesar 0,9144 gram. Nilai tersebut masuk dalam rentang nilai berat jenis minyak atsiri yaitu antara 0,696-1,18 (Ketaren, 1985).

Indeks bias merupakan perbandingan antara kecepatan cahaya di dalam udara dengan kecepatan cahaya di dalam minyak atsiri pada suhu tertentu. Nilai indeks bias minyak atsiri rimpang temu putih sebesar 1,5021. Nilai ini masuk ke dalam rentang nilai indeks bias cahaya minyak atsiri yaitu antara 1,5020 - 1,5190 (Ketaren, 1985). Nilai 
indeks bias dipengaruhi beberapa faktor, salah satunya dengan adanya air dalam kandungan minyak tersebut. Semakin banyak kandungan airnya, semakin kecil nilai indeks biasnya (Guenter, 1987).

Pemeriksaan analisis dengan GC-MS menghasilkan kromatogram dengan 29 puncak senyawa seperti pada Gambar 1.

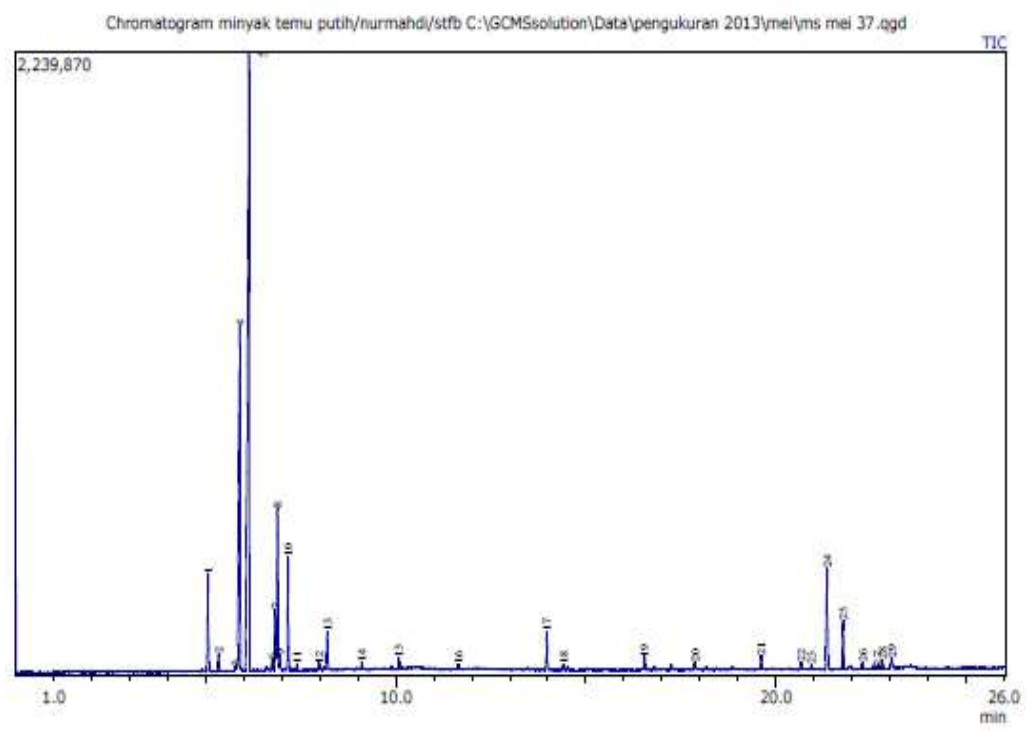

Gambar 1. Kromatogram GC-MS minyak atsiri rimpang temu putih

Penentuan komposisi minyak atsiri temu putih (Curcuma zedoaria (Berg.) Roscoe) menunjukkan hasil spektrum massa dari masing-masing puncak unknown dibandingkan dengan spektrum massa senyawa yang ada pada daftar library GC-MS. Gambar 1 menunjukkan deteksi berdasarkan spektra MS yang dihasilkan sebanyak 29 jenis senyawa yang massa rumus senyawa sampel sesuai dengan spektrum standar. Senyawa tersebut adalah $\alpha$-pinen $(3,82 \%)$, kampen $(0,62 \%), \beta$-pilandren $(0,30 \%), \beta$ pinen $(21,64 \%), \beta$-mirsen $(43,78 \%)$, benzene $(0,36 \%)$, dl-Limonen $(2,58 \%), 1,8$ Sineol $(6,79 \%)$, cis-Osimen $(0,56 \%), 1,3,6$-Oktatrien $(4,49 \%), 1,4$-Sikloheksadin $(0,23 \%), \alpha-$ Terpinolen $(0,31 \%)$, Furan $(1,45 \%)$, Kamfor $(0,26 \%)$, $\alpha$-Tujenal $(0,48 \%)$, $\alpha$-Fensil asetat $(0,17 \%)$, Kariopilen $(1,66 \%)$, trans- $\beta$-fernesen $(0,24 \%)$, Kariopilen Oksida $(0,58 \%)$, Longifolenaldehid (0,36\%), Albicanol (0,61\%), (E,E,E)-3,7,11,15Tetramethylhexadeca-1,3,6,10,14-pentaene $(0,23 \%)$, d-Nerolidol $(0,18 \%)$, Sikloheksen $(4,84 \%)$, Farnesol (0,18\%), (E,E,E)-3,7,11,15-Tetramethylhexadeca-1,3,6,10,14pentaene $(0,22 \%)$, Geranylgeraniol $(0,16 \%)$, Aromadendrenepoksida $(0,35 \%)$, dan Geranylgeraniol $(0,50 \%)$.

Pada formulasi sediaan emulgel dibuat 4 formula yang berbeda dengan variasi konsentrasi PEG 8 beeswax 6,5\%,7\%,7,5\%, dan 8\%, seperti yang ditunjukkan pada Tabel III . 
Tabel III. Formulasi emulgel yang mengandung minyak atsiri rimpang temu putih

\begin{tabular}{lcccc}
\hline \multirow{2}{*}{ Bahan (\%) } & \multicolumn{4}{c}{ Formula } \\
\cline { 2 - 5 } & F1 & F2 & F3 & F4 \\
\hline Minyak Atsiri Temu putih & 1 & 1 & 1 & 1 \\
PEG 8 Beeswax & 6,5 & 7 & 7,5 & 8 \\
Parafin & 25 & 25 & 25 & 25 \\
Carbopol 940 & 0,1 & 0,1 & 0,1 & 0,1 \\
TEA & 0,16 & 0,16 & 0,16 & 0,16 \\
DMDM hydantoin & 0,5 & 0,5 & 0,5 & 0,5 \\
Aquades ad & 100 & 100 & 100 & 100 \\
\hline
\end{tabular}

Tabel III memperlihatkan bahwa konsentrasi PEG 8 beeswax berbeda-beda yang merupakan emulsifying wax yaitu suatu agen pengemulsi sintetis yang termasuk surfaktan nonionik hidrofilik, juga membantu terbentuknya emulsi pada sediaan emulgel. Kemudian dilakukan uji evaluasi yaitu pengamatan organoleptik, sentrifugasi, $\mathrm{pH}$, viskositas dan uji hedonitas sediaan. Hasil pengamatan organoleptik ditunjukkan pada Tabel IV.

Tabel IV. Hasil pengamatan organoleptis emulgel mengandung minyak atsiri rimpang temu putih selama 28 hari penyimpanan

\begin{tabular}{|c|c|c|c|c|c|c|c|c|}
\hline \multirow{2}{*}{ Formula } & \multirow{2}{*}{ Pengamatan } & \multicolumn{7}{|c|}{ Hari ke- } \\
\hline & & 1 & 3 & 5 & 7 & 14 & 21 & 28 \\
\hline \multirow[t]{3}{*}{ F1 } & Konsistensi & HK & HK & HK & HK & HK & HK & HK \\
\hline & Warna & PS & PS & PS & PS & PS & PS & PS \\
\hline & Bau & BK & BK & BK & BK & BK & BK & BK \\
\hline \multirow[t]{3}{*}{ F2 } & Konsistensi & HK & HK & HK & HK & $\mathrm{HK}$ & HK & $\mathrm{HK}$ \\
\hline & Bau & PS & PS & PS & PS & PS & PS & PS \\
\hline & Warna & BK & $\mathrm{BK}$ & BK & BK & BK & $\mathrm{BK}$ & BK \\
\hline \multirow[t]{3}{*}{$\mathbf{F 3}$} & Konsistensi & HK & $\mathrm{HK}$ & $\mathrm{HK}$ & $\mathrm{HK}$ & HK & $\mathrm{HK}$ & HK \\
\hline & $\mathrm{Bau}$ & PS & PS & PS & PS & PS & PS & PS \\
\hline & Warna & BK & $\mathrm{BK}$ & $\mathrm{BK}$ & $\mathrm{BK}$ & $\mathrm{BK}$ & BK & $\mathrm{BK}$ \\
\hline \multirow[t]{3}{*}{ F4 } & Konsistensi & $\mathrm{HK}$ & $\mathrm{HK}$ & $\mathrm{HK}$ & $\mathrm{HK}$ & HK & HK & HK \\
\hline & $\mathrm{Bau}$ & PS & PS & PS & PS & PS & PS & PS \\
\hline & Warna & BK & $\mathrm{BK}$ & BK & $\mathrm{BK}$ & BK & BK & BK \\
\hline
\end{tabular}

Keterangan:

F1 = Mengandung Emulsifying wax 6,5\%

F2 = Mengandung Emulsifying wax 7\%

F3 = Mengandung Emulsifying wax 7,5\%

F4 = Mengandung Emulsifying wax 8\%

HK = Homogen, Kental

PS = Putih Susu

TB = Tidak Bau

BK $\quad=$ Bau Khas Minyak Atsiri

Tabel IV menunjukkan hasil pengujian organoleptik yang meliputi konsistensi, warna, dan bau yang mengalami penyimpanan selama 28 hari tidak mengalami perubahan yang signifikan dari konsistensi, warna, dan bau. Kemudian dilakukan 
evaluasi pengamatan $\mathrm{pH}$ yang diukur pada hari ke 1, 3, 5, 7, 14, 21, dan 28 hari. Hasil pengamatan $\mathrm{pH}$ seperti yang ditunjukkan pada Gambar 2.

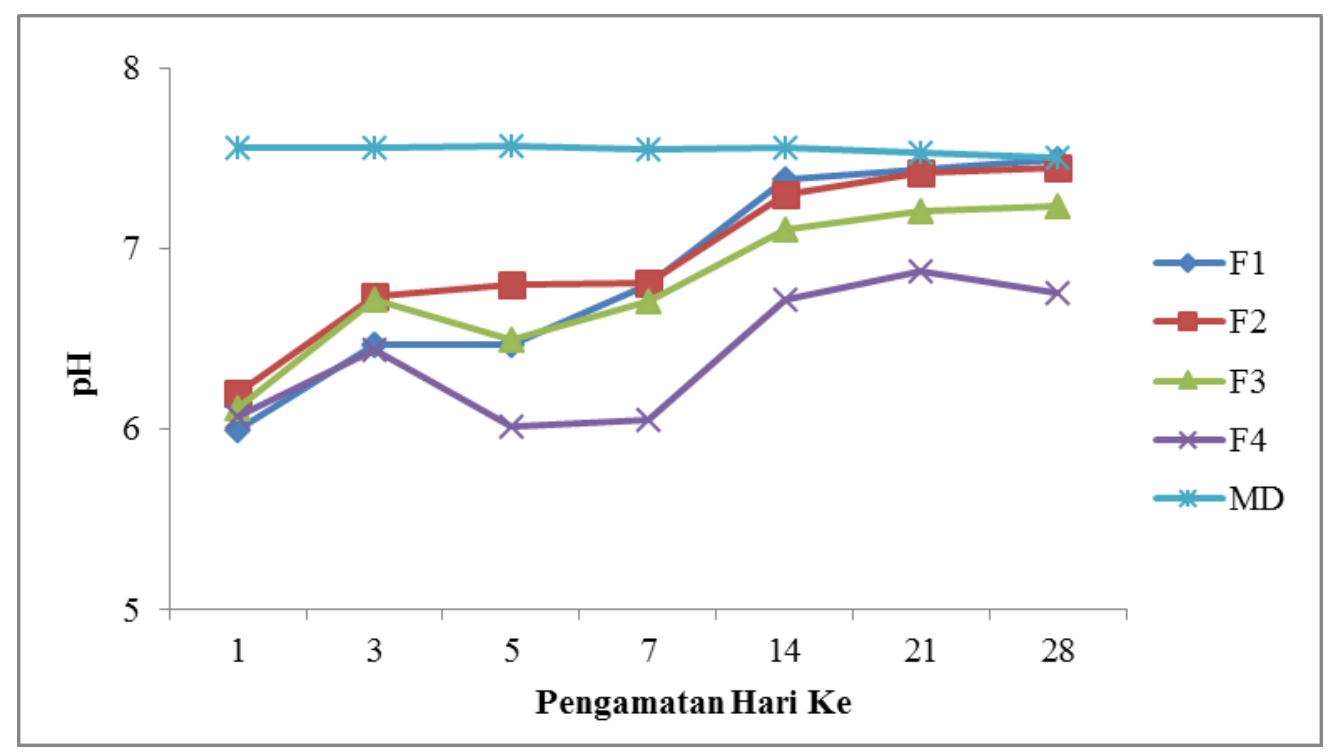

Gambar 2. Grafik hasil rata-rata pH emulgel selama 28 hari

Gambar 2 menunjukkan bahwa dari hasil pengamatan $\mathrm{pH}$ selama 28 hari terdapat perbedaan signifikan dari masing-masing formula, dimana formula 1 paling mendekati dengan sediaan emulgel merk dagang (MD) yaitu pada konsentrasi PEG 8 beeswax $6,5 \%$. Kemudian dilakukan evaluasi pengukuran viskositas yang diukur pada hari ke-1, 3, 5, 7, 14, 21, dan 28 hari penyimpanan. Hasil pengukuran $\mathrm{pH}$ ditunjukkan pada Gambar 3.

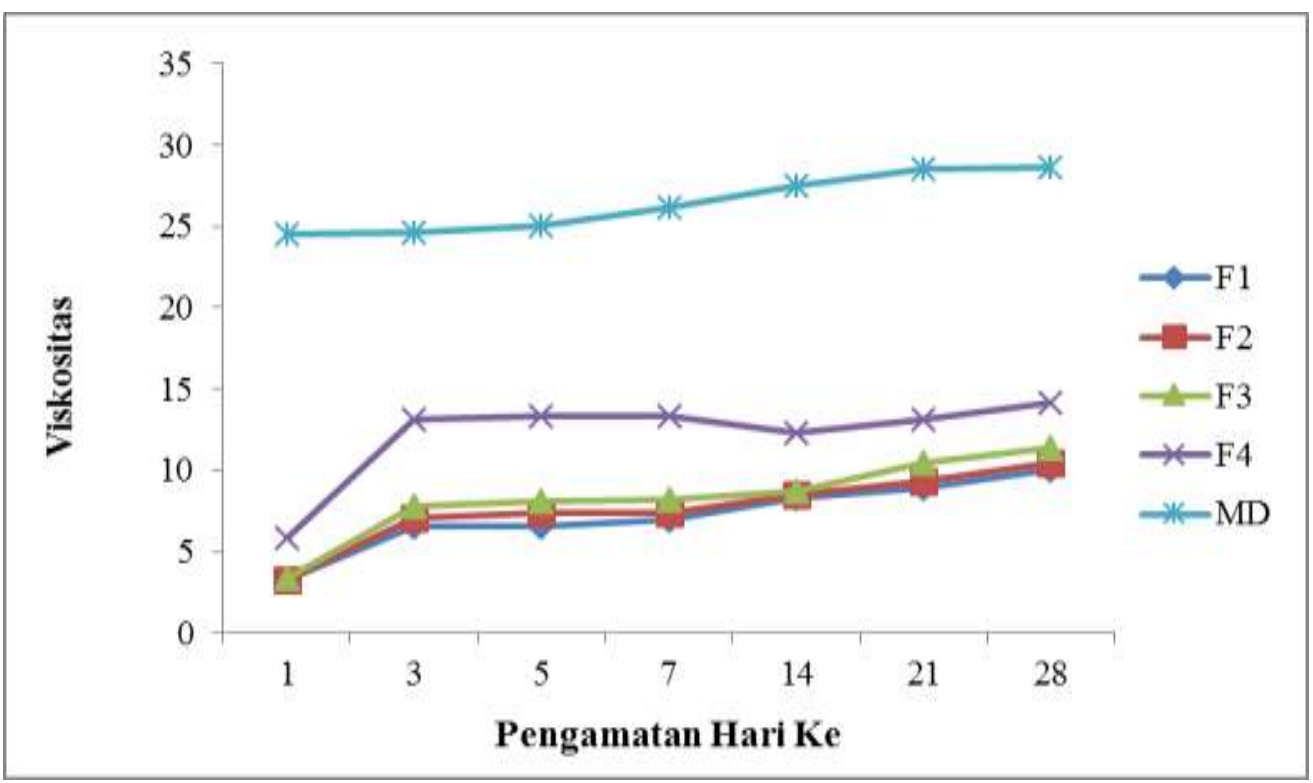

Gambar 3. Grafik hasil rata-rata viskositas emulgel selama 28 hari penyimpanan 
Gambar 3 menunjukkan hasil pengukuran viskositas emulgel selama 28 hari penyimpanan terdapat perubahan kekentalan yang signifikan. Hal ini terjadi karena berbagai faktor, di antaranya adalah suhu, tekanan, dan kohesi. Suhu berpengaruh karena pada saat penyimpanan suhu tidak teratur, viskositas menurun jika suhu dinaikkan dan viskositas meningkat jika suhu diturunkan (J.Sinko \& N.Martin, 2006). Selanjutnya dilakukan evaluasi pengujian sentrifugasi pada kecepatan 2500, 3000, dan 3700 rpm. Hasil pengujian sentrifugasi ditunjukkan pada Gambar 4.
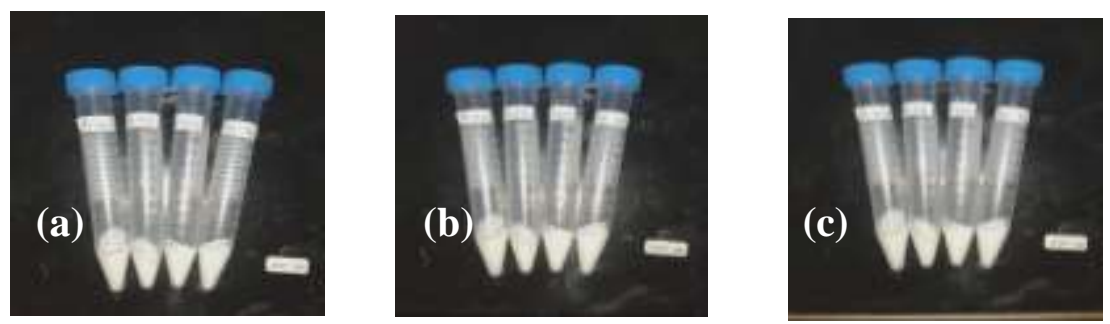

Gambar 4. Pengamatan setelah sediaan dilakukan sentrifugasi

Keterangan:

(a) : kecepatan $2500 \mathrm{rpm}$

(b) : kecepatan $3000 \mathrm{rpm}$

(c) : kecepatan $3700 \mathrm{rpm}$

Gambar 4 menunjukkan bahwa perlakuan sentrifugasi tidak menunjukkan terjadinya pemisahan fasa emulgel pada kecepatan sentrifugasi dari 2500, 3000, dan $3700 \mathrm{rpm}$ (rotasi per menit) pada formula 1, 2, 3, dan 4. Suatu sediaan yang disentrifugasi pada $3700 \mathrm{rpm}$ dengan radius sentrifus $10 \mathrm{~cm}$ dan waktu 5 jam setara dengan efek gravitasi untuk kira-kira satu tahun. Berdasarkan konversi, didapat bahwa sentrifugasi dengan kecepatan $2500 \mathrm{rpm}$ selama 5 jam setara dengan efek gravitasi sekitar 8 bulan. Sedangkan untuk kecepatan $3000 \mathrm{rpm}$ setara dengan efek gravitasi sekitar 10 bulan (J.Sinko \& N.Martin, 2006).

Pengujian kualitatif menggunakan Kromatografi Lapis Tipis (KLT) dilakukan pada minyak atsiri rimpang temu putih dan emulgel yang mengandung minyak atsiri rimpang temu putih. Hasil KLT disajikan dalam Gambar 5.

Pada Gambar 5, pengujian kualitatif emulgel dengan KLT dilakukan pada minyak atsiri rimpang temu putih dan sedian emulgel yang mengandung minyak atsiri rimpang temu putih. Pengujian kualitatif pada minyak atsiri yaitu pertama minyak atsiri ditotolkan pada plat silika gel $\mathrm{GF}_{254}$, kemudian dikembangkan dengan menggunakan nheksan:etil asetat dengan perbandingan 9:1. Pengembang ini merupakan pengembang yang sesuai untuk minyak atsiri dari rimpang temu putih. Pemantauan dengan menggunakan lampu UV 254 terilhat adanya bercak yang muncul pada setiap formula yang ditotolkan pada plat silika gel $\mathrm{GF}_{254}$. 

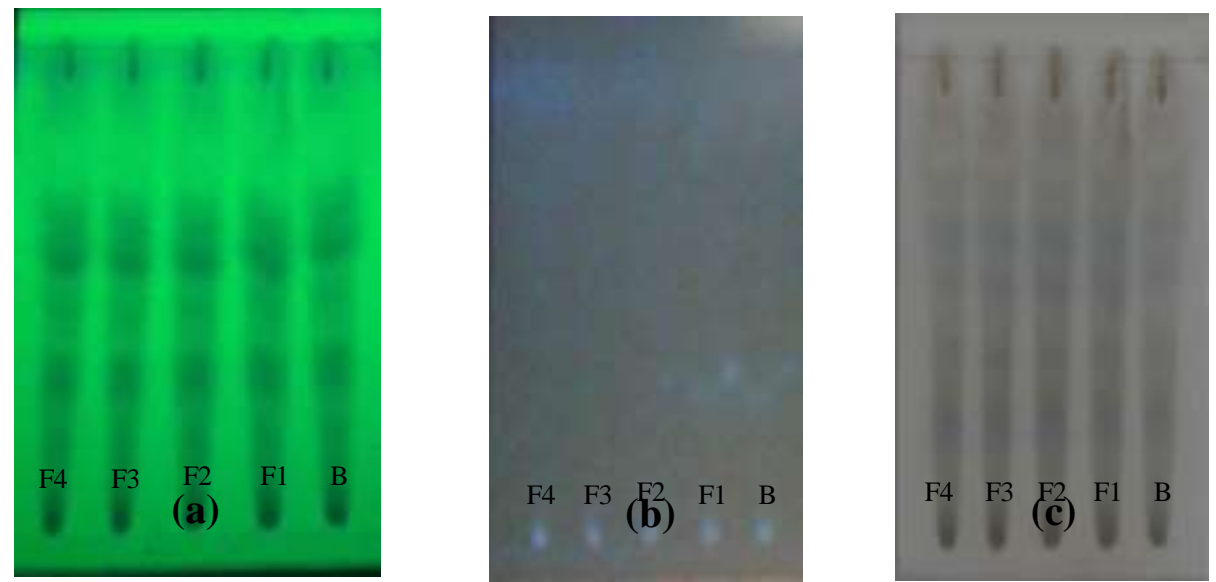

Gambar 5. Hasil pengujian kualitatif minyak atsiri dan emulgel dengan KLT

Keterangan :

(a) : lampu UV $254 \mathrm{~nm}$

(b) : lampu UV $366 \mathrm{~nm}$

(c) = penampak bercak vanilin sulfat

$\mathrm{B}=$ minyak atsiri rimpang temu putih

$\mathrm{F} 1=$ emulgel konsentrasi PEG 8 beeswax 6,5\% mengandung minyak atsiri temu putih

F2= emulgel konsentrasi PEG 8 beeswax 7\% mengandung minyak atsiri temu putih

$\mathrm{F} 3=$ emulgel konsentrasi PEG 8 beeswax 7,5\% mengandung minyak atsiri temu putih

$\mathrm{F} 4=$ emulgel konsentrasi PEG 8 beeswax $8 \%$ mengandung minyak atsiri temu putih

Tabel V. Nilai Rf kromatogram minyak atsiri rimpang temu putih

\begin{tabular}{lcl}
\hline Nilai Rf & No. Bercak & Pereaksi warna vanilin sulfat \\
\hline 0,28 & 1 & Hijau tua \\
0,46 & 2 & Ungu \\
0,6 & 3 & Hijau muda \\
0,76 & 4 & Biru \\
0,9 & 5 & Ungu \\
\hline
\end{tabular}

Tabel V menunjukkan pemantauan dengan penampak bercak vanilin sulfat muncul beberapa bercak berwarna ungu menunjukkan adanya kandungan terpenoid pada minyak atsiri tersebut, kemudian pengujian kualitatif pada sediaan emulgel yang mengandung minyak atsiri yang terdiri dari 4 formula yang sama konsentrasi minyak atsirinya, masing-masing formula. Pada saat pemantauan dengan penampak bercak vanilin sulfat muncul bercak berwarna ungu. Hal ini menunjukkan bahwa emulgel masih memiliki kandungan minyak atsiri. Selanjutnya dilakukan uji hedonitas sediaan dengan cara mengoleskan sediaan ke punggung tangan 20 orang sukarelawan. Hasil uji hedonitas ditunjukkan pada Gambar 6. 


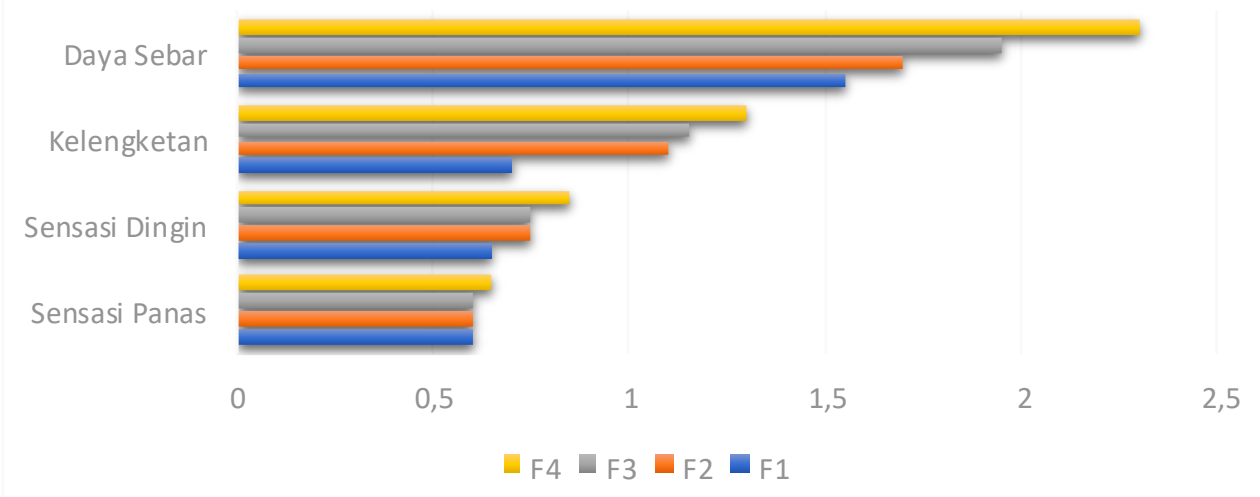

Gambar 6. Hasil uji hedonitas sediaan emulgel

Gambar 6 menunjukkan bahwa semua formula sediaan emulgel yang mengandung minyak atsiri rimpang temu putih tidak menyebabkan iritasi pada kulit sukarelawan. Hal tersebut ditandai dengan tidak adanya gatal-gatal, pembengkakan dan kemerahan. Namun, ada sukarelawan yang menyatakan sensasi panas dan lengket, karena sifat minyak atsiri yang khas apabila dioleskan terasa panas. Sehingga dari hasil tersebut dapat disimpulkan bahwa sediaan emulgel yang dibuat masih dalam batas aman untuk digunakan. Penggunaan sediaan topikal yang mengandung PEG 8 beeswax ketika dilakukan uji iritasi kulit pada manusia menunjukkan tidak menimbulkan iritasi dengan konsentrasi $0,2 \mathrm{ml}$ murni melalui test patch pada 30 sukarelawan manusia pada bagian lengan kulit (Fruijtier-Pölloth, 2005).

Hasil pengujian statistik analysis of variation (ANOVA) pada program IBM SPSS Statistics 20 digunakan untuk mengetahui adanya perbedaan yang bermakna atau tidak pada $\mathrm{pH}$ kelompok sediaan uji. Adapun uji yang digunakan adalah uji $\mathrm{F}$ dengan tingkat signifikansi $\alpha=5 \%$. Hasil menunjukkan $F_{\text {hit }}(23,117)>F_{\text {tab }}(2,2507)$, artinya ada perbedaan bermakna. Kemudian dilanjutkan dengan analisis Multiple Comparisons (Post Hoc) pada tingkat signifikansi $\alpha=5 \%$ dengan uji LSD. Hasil pengujian statistik ini menunjukkan ada perbedaan bermakna antara rata-rata $\mathrm{pH}$ sediaan emulgel pada semua formula. Untuk mencari data $\mathrm{pH}$ yang terbaik di antara kelompok sediaan uji, maka dibandingkan dengan produk yang ada di pasaran dengan merk tertentu, maka dilakukan uji Duncan. Berdasarkan uji Duncan formula 2 (F2) yang terbaik, di antara formula yang lain, karena nilai rata-rata $\mathrm{pH}$ tersebut paling mendekati dengan MD (merk dagang).

Hasil uji $F$ pada data viskositas diperoleh $F_{\text {hit }}(273,853)>F_{\text {tab }} \quad(2,2507)$ menunjukkan bahwa ada perbedaan antar formula. Untuk mencari data yang berbeda secara bermakna antara 2 kelompok sediaan uji, maka dilakukan analisis Multiple Comparisons (Post Hoc) pada tingkat signifikansi $\alpha=5 \%$ dengan uji LSD. Disimpulkan bahwa ada perbedaan bermakna antara rata-rata viskositas sediaan emulgel pada semua formula. Untuk mencari data viskositas yang terbaik di antara kelompok sediaan uji, maka dibandingkan dengan produk yang ada di pasaran dengan merk tertentu, maka dilakukan uji Duncan. Berdasarkan uji Duncan formula 4 (F4) yang terbaik, di antara formula yang lain, karena nilai rata-rata viskositasnya paling mendekati dengan MD (Merk Dagang). 


\section{KESIMPULAN}

Berdasarkan hasil penelitian, dari hasil uji evaluasi sediaan meliputi pengamatan organoleptik, $\mathrm{pH}$, viskositas, sentrifugasi, dan uji hedonitas maka dapat disimpulkan bahwa formulasi emulgel mengandung minyak atsiri rimpang temu putih (Curcuma zedoaria) yang paling baik, stabil, dan aman dalam penggunaannya adalah formula 4 dengan konsentrasi PEG 8 beeswax $8 \%$.

\section{DAFTAR PUSTAKA}

Fruijtier-Pölloth, C., 2005, Safety assessment on polyethylene glycols (PEGs) and their derivatives as used in cosmetic products. Toxicology, 214(1-2), 1-38. https://doi.org/10.1016/j.tox.2005.06.001

Guenter, E., 1987, Minyak Atsiri. Jakarta: UI-Press.

J.Sinko, P., \& N.Martin, A., 2006, Martins Physical pharmacy and pharmaceutical sciences. Lippincott williams \& Wilkins,wolter kluwer. https://doi.org/10.1097/00000441-196101000-00040

Ketaren., 1985, Pengantar Teknologi Minyak Atsiri. PN Balai Pustaka. Jakarta.

Mansjoer, S., 1997, Efek Antiradang Minyak Atsiri Temu Putih (Curcuma zedoaria Rosc., Zingiberaceae) terhadap Udem Buatan pada Tikus Putih Betina Galur Wistar: The Antiinflammatory Effect Of The Essential Oil Of "Temu Putih." Jurnal i-lib UGM. Majalah Farmasi Indonesia. Retrieved from https://repository.ugm.ac.id/24549/

Meenakshi, D., 2013, Emulgel A novel approach to topical drug delivery. International Journal of Pharma and Bio Sciences, 4(1), 847-856.

Rita, W. S., 2010, Isolasi, Identifikasi, dan Uji Aktivitas Antibakteri Senyawa Golongan Triterpenoid Pada Rimpang Temu Puth (Curcuma zedoaria (Berg) Roscoe). Jurnal Kimia, 4(1), 20-26.

Rosyad, P. G. Y., 2009, Formulasi Gel Obat Jerawat Minyak Atsiri Daun Jeruk Nipis (Citrus aurantifolia, Swingle) dan Daya Antibakteri (Propionibacterium acne) Secara In Vitro. Surakarta: Fakultas Farmasi Universitas Muhammadiyah. Retrieved from http://eprints.ums.ac.id/3378/1/K100040233.pdf

Singla, V., Saini, S., Joshi, B., \& Rana, A. C. , 2012, Emulgel: A new platform for topical drug delivery. International Journal of Pharma and Bio Sciences, 3(1), P485-P498.

Wasitaatmadja, S. M., 1997, Penuntun Ilmu Kosmetik Medik. Jakarta: UI-Press. 